\title{
Airport Curbside and Parking Area Operations at BIA -Analysis of User Behavior
}

\author{
S.D.B Galagedera, H.R Pasindu and J.M.S.J. Bandara
}

\begin{abstract}
Airport curbside, where travelers and their baggage enter and exit the terminal, and the designated parking area are important components in airport land-side facilities. Passengers expect safe and efficient roadway operations even as volumes increase, but the design and capacity of the curbside are often constrained by the terminal building and the proximity of on-airport land-side infrastructure. The operating characteristics of airport terminal curbside differ significantly from those of most other roadways due to several reasons such as vehicle dwell time, maneuver vehicles to and from adjacent lane, variation in demand etc. The capacity of a curbside roadway is defined both by the number of vehicles that can be accommodated while stopping to pick up or drop off passengers and the number that can be accommodated while traveling past the curbside in the through lanes. Therefore a study of operations at curbside and parking area is important to identify issues related to existing and future demand levels.
\end{abstract}

The main focus of the paper is on the evaluation of vehicle operations and passenger behavior at the BIA terminal access roadway, weaving segment, arrival and departure curbside roadways and terminal car park. Analysis of vehicular traffic, travel mode choices, and curbside roadway vehicle queues, vehicle dwelling times, passenger occupancy time at curbs and passenger processing and walking times will provide useful information for developing plans for operational improvements as well as for future expansions. Using the available data, the demand and the capacity at these facilities are evaluated to estimate the existing level of service. In addition, measures were identified to improve the operational efficiency of these facilities and design improvements are proposed to ensure good operational efficiency for the forecast future demand.

Key words: Airport terminal, curbside, parking area.

\section{Introduction}

Bandaranaike International Airport (BIA) (also known Colombo International Airport) (IATA: CMB, ICAO: VCBI) is one of the two international airports serving Sri Lanka. BIA is located in Katunayake, $31.7 \mathrm{~km}$ north of Colombo. It is administered by Airport and Aviation Services Ltd (AASL). It is the base for Srilankan Airlines, the national carrier of Sri Lanka, and Mihin Lanka, the budget airline of Sri Lanka.

The currently experienced passenger movement of 6 million is likely to double within the next 5 - 9 years (AASL Annual report, 2012). The new terminal to be commissioned under the expansion project would double the passenger handling capabilities of the BIA. A policy change is planned by the government aiming to boost air cargo and transshipment aspects in the aviation sector and develop Sri Lanka as a regional aviation hub.

\section{Research Objective}

This research mainly focuses on airport curbside and roadway operations. Roadway operations depend upon several factors such as air passenger origin and destination within the country, income level, age, purpose of journey (education, work, immigration, leisure etc.) etc. Curbside and roadways operations are mainly a function of vehicle operations and vehicle operations differ with passenger behaviors, driver behaviors and Flight schedules. Furthermore both air passenger and vehicle passenger (guests of the

Eng. S.D.B Galagedera, B.Sc. Eng. (Moratuwa). MIET, Mechanical Engineer, LTL Holdings Ltd.

Dr. H.R Pasindu BSc Eng. (Moratuwa), PhD (Singapore), Senior Lecturer, Department of Civil Engineering,

University of Moratuwa.

Prof. J.M.S.J Bandara BSc Eng.(Moratuwa), PhD

(Canada), Senior Lecturer, Department of Civil Engineering, University of Moratuwa 
passenger) behaviors affect the curbside roadway functions.

Airport roadway facilities and relevant operational activities are considered. The effects of activities for the airport roadway facilities are identified and performance levels of facilities are evaluated. The existing inefficiencies in roadway facilities, safety issues and lack of facilities are also discussed. The passenger demand at the year 2020 is projected and evaluates the performances of existing facilities for the projected passenger demands. It will be a gauge for future facility expansions, hence necessary parameter for improvement measures need to be implemented.

\section{Literature Review}

\subsection{Airport Curbside and Roadways}

Airport roadways which consist all means of roads in an airport, are a unique class of roadways specific to airport operations. Large numbers of vehicle volumes daily operate with a mix of un-familiar and familiar drivers, while curbside roadways operate at much slower speeds, as drivers attempt to maneuver into and out of curbside spaces.

BIA landside roadways serve for airline passengers and visitors, employees owing to various service provisions in the airport itself, air cargo and mail, and operation and maintenance activities. Several types of vehicles use airport roadways and they include private vehicles, rental cars, taxicabs, three wheelers, tourist coaches.

Airport roadways which links different land uses are most prominent facilities for all airport users. The airport roadway network consists of access roadway, departure and arrival curbside roadway, weaving sections, and circulation roadway. Airport entrance to exit via the curbside area is the highest vehicle demanding road segment with remarkable over $75 \%$ out of the total demand(ACRP 40, 2010). Airport access roadway maintains the highest volumes of airline passenger-generated traffic and the curbside roadways are one-way roadways located immediately in front of the terminal buildings where vehicles stop to pick up and drop off passengers and their baggage. Curbside roadways typically consist of inner lane(s), adjacent maneuvering lane, and through or bypass lanes. The circulation roadway is to serve to travel from airport exit or from terminal car park to airport access roadway within the airport premises itself.

Airport roadways are having noticeable differences as compared to non-airport roadways. The BIAs $80 \%$ of passengers (AASL annual report, 2011) fall to infrequent flyers (fewer than four times per year), and a high proportion of corresponding motorists could also be considered as unfamiliar to airport roadways and facilities. Furthermore, Emotional stress becomes serious because of the motorists who are close relatives of enplaning passengers perform with the highest emotional feelings before and after dropping off air passengers. Congested airport roadways, closely spaced decision points, and complex signs can add to this stress and discomfort.

Airport Cooperative Research Program (ACRP) conducts research studies related to the aviation industry on design and operational aspects of airports. In a recent study conducted by ACRP has evaluated the performance of curbside and roadway area of a number of airports in the world and has identified set of parameters to categorize their service levels and performances. ACRP is not a standard and it presents guidelines to evaluate performances in different service facilities and suggestions to overcome typical drawbacks and issues in airport facilities. BIA falls to the small hub airport category under the ACRP performance level criteria and is used those guidelines to analyze the BIA roadway performances.

\subsection{Traffic Characteristics}

\section{Dwell time}

This is the amount of time a vehicle spends parked at a curbside lane (or other passenger loading or unloading area). Typically, the dwell time is the length of time between when the driver parks (i.e., the vehicle comes to a complete stop) and when the driver first attempts to rejoin the traffic stream. In this study, active dwell time which reflects the time difference between when a vehicle first stops at a curbside until it leaves the curbside is used.

\section{Modal choices}

This is to convert person trips into vehicle trips, it is necessary to first determine the travel modes used by airline passengers and visitors (or the percentage of passengers using each available travel mode). 


\section{Vehicle occupancies}

Vehicle occupancies (the number of passengers per vehicle) are used to translate or convert "person trips" by travel mode into vehicle trips. When analyzing airport roadways, vehicle occupancies represent the number of airline passengers in each.

\section{Peak-hour factors}

Airport roadway traffic is not uniformly distributed over a typical peak hour or other peak period. Peak-hour (adjustment) factors are used to translate non-uniform flows into equivalent hourly flows to allow for the analyses of roadways exhibiting such nonuniform peaks.

\section{Parking Volume}

Number of vehicles actually accommodated in the parking premises in a given time duration is called as volume. The volume changes with the parking duration.

\section{Parking Load}

Parking load define the summation of number of all vehicles parking in an hour. In this particular term vehicles in the premises are repetitively taken in to the account in every concerned hour and therefore unit is vehicle hours.

\subsection{Performance Evaluation}

Airport facilities are looked in to its adequacy to cater the demand level. This concept is called as Level of Service analysis (LOS), which is a quality measure describing operational conditions within a traffic stream by considering speed and travel time, freedom to maneuver, traffic interruptions, and comfort and convenience. There are six LOS categories from LOS A to LOS F due to different traffic conditions and LOS A represents operations where free-flow speeds prevail and LOS F represents breakdowns in vehicular flow.

Curbside utilization indicates if spare capacity is available to serve additional demand and surges in demand. Typically, a utilization factor of 1.30 (see calculations) or less (65\% of the capacity of the curbside loading/unloading lanes) is a desirable planning target for new curbside roadways and 1.70 is acceptable for peak hours for existing facilities. Utilization is an indicator of curbside roadway level of service. LOS C is a desirable planning target for medium or small-hub airports.

\section{Field Surveys}

Data collection is the vital component in this study because most of the information had to be collected from field surveys and limited research have been done on this particular aspect of BIA operations. BIA's fight schedule is the basis of all operational aspects and BIA releases its monthly fight schedule for each month. The survey for this study was conducted during twelve days for 24 hours to cover up the full aircraft operations pattern. The survey focused on Airport access roadway, Airport departure and arrival curbside roadways, Airport terminal car park, Airport circulation roadway, Airport weaving section and Airport exit.

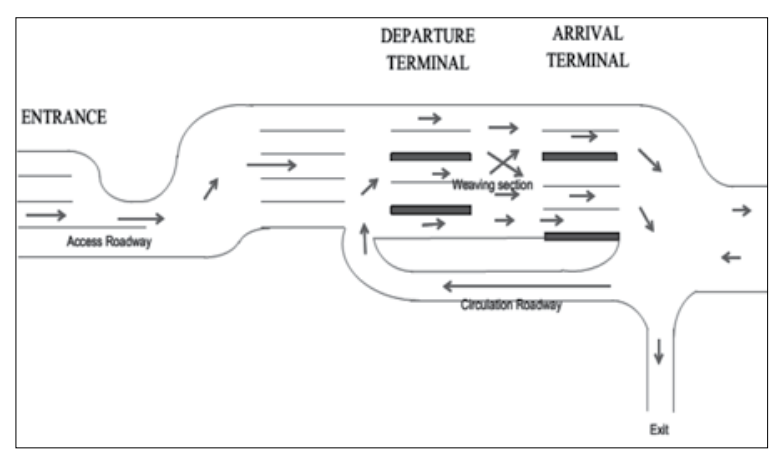

Figure 1 - BIA roadway configuration

\subsection{Airport Operation Data}

The total passenger movement via BIA is increasing almost $15-20 \%$ of rate for the last three years (Refer Figure 4.2). It was seven (7)million total passenger movements at the end of year 2012 including 1.2 million transit passengers. The highest passenger movements' records in the months of August and December (refer Figure 4.3) due to the tourist season and annual holiday vacations of foreign employees. There are $130-140$ total aircraft movements (both departures and arrivals) in a day, and 46484 total aircraft movements per annum(AASL Annual Report,2011). It reveals that, on average there are 150 air passengers in an aircraft operating to and from the BIA.

\subsection{Airport roadways Access roadway}

There are on average 7,100 vehicles daily use the Airport access roadway segment and highest vehicle movement 591 vehicles/hour records during the 22:00 to 23:00 hour in every day. However, cars (all vehicles having four numbers of seating capacities) and vans (vehicles having more than four seats other 
than busses) are having similar modal choice of $39 \%$; Three wheelers $20 \%$ and buses having the lowest $2 \%$.

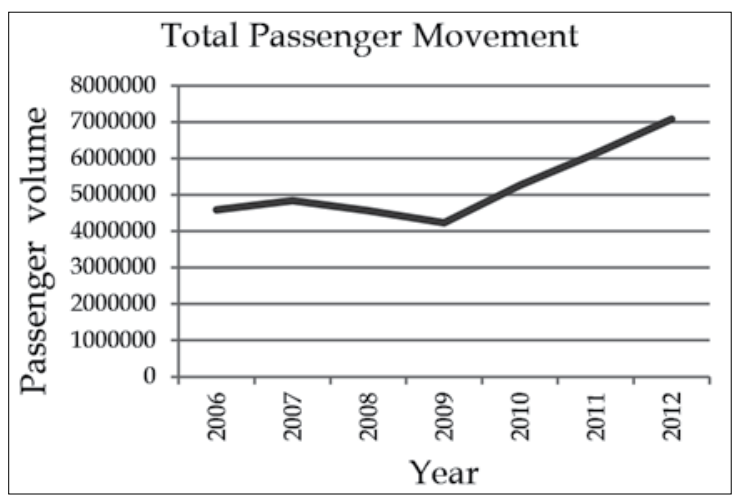

Figure 2 - Passenger Movement (Source: BIA Internal Data Records)

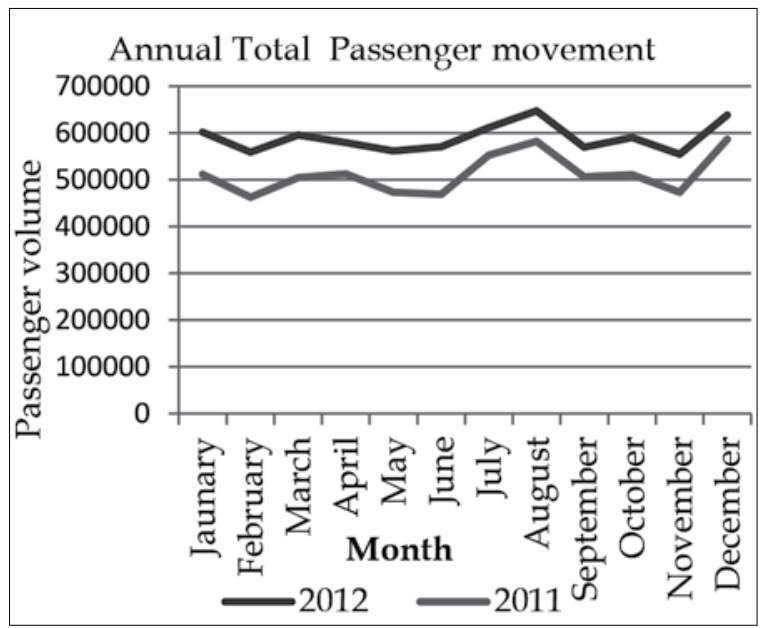

Figure 3 - Passenger movement (Source: BIA Internal Data Records)

\section{Arrival curbside}

Vehicle speeds at the arrival porch noticeably decrease since vehicle drivers looking for their passengers along the curb. Most of the vehicles always attempt to stop at the closest to their passengers. There are inner and outer porch segments doubled the available curb length. However, the outer porch curbside is fully occupied by BIA taxies most of the time. (Airport directly handled taxi service). They are having higher dwelling time due to waiting for passengers. Therefore, the effective number of parking slots drops to 20 even though there are 36 slots available. At grade pedestrian crossings at the arrival porch entrance lead to vehicle queues and duty free shop item deliveries enhance the congestion further.

According to the survey, there are total 3,702 numbers of daily vehicles moves in to the arrival curbside and the highest number of 329 vehicles recorded during the 5:00- 6:00 hour in the morning. Dual purpose vehicles such as vans and jeeps contribute to $57 \%$ of modal share and $42 \%$ are cars, and the balance $1 \%$ are heavy vehicles delivering duty free goods. Nearly $75 \%$ of vehicles use the inner curbside roadway and remaining $25 \%$ use outer porch area.

\section{Departure curbside}

The highest vehicle movement in to the departure curbside roadway is during the 22:00 to 23:00 hour and it is 296 vehicles. The observed total vehicle movement is 2,980 per day and there are times that no vehicles in the departure curbside. Nearly $41 \%$ of vehicles arrivals are cars and $36 \%$ of vehicles are dual purpose vehicles. It was notable that $23 \%$ uses three wheelers.

\subsection{Curb}

\section{Arrival curb}

BIAs' arrival curb congestion closely follow the arrival flight schedule and the highest flight arrivals during 4:00 - 6:00hours and 10:00, 17:00, and 22:00 hours in each day, there are no significant arrivals in the rest of the hours. It is found that the curb congestion arises after averagely 40 minutes later the aircraft landings (from peak to peak distance of arrival curbside vehicle accumulation graph and arrival flight graph).

The average vehicle dwelling time at the arrival porch in peak hours is around 2.2 minutes and in non-busy hours is 3.5 minutes. The passenger occupancy level for both peak and non-peak hours are 5.4 passengers per vehicle. At the BIA, outgoing vehicles from the arrival curbside carry 4.5 baggage pieces on average and further analysis on cars and dual purpose vehicles reveal that averages are 3.7 and 4.9 baggage respectively. A vehicle stays 2.1 minutes at the curbside to pick up single air passenger and 2.4 baggages are carried by one air passenger. There are three persons arrive to the arrival curb to receive one air passenger and this figure vary with air passenger characteristics such as age and origin of travel. Number of baggage and vehicle dwelling time for an air passenger is almost equivalent for all vehicle types and they do not depend upon types of vehicles at all.

When number of passengers in a group increases, their waiting time at the arrival curb proportionally increases. However, it could be observed that when there are Middle East based flight passengers, their waiting times are much higher. Even though maximum two 
number of arrival flights from Middle East or Europe in a particular hour, the arrival curb getting congested since passenger origins effectively contribute.

\section{Departure curb}

BIA's departure curbside roadway vehicle accumulation follows the departure flight schedule with three to four hour lead time and is getting congested at the 21:00-22:00 hour in night in every day. The curb overcrowding takes place when there are number of European flights departing at once.

The average vehicle dwelling time at the departure curbside in peak hours is 3.0 minutes and further analysis for cars and dual purpose vehicle record as 2.9 minutes and 3.1 minutes respectively. Average occupancy is 3.9 passengers per vehicle. When departure passengers are leaving as groups, they stay much longer times at the departure curb and therefore the corresponding dropping off vehicles may also dwell proportionally higher durations at the curbside.

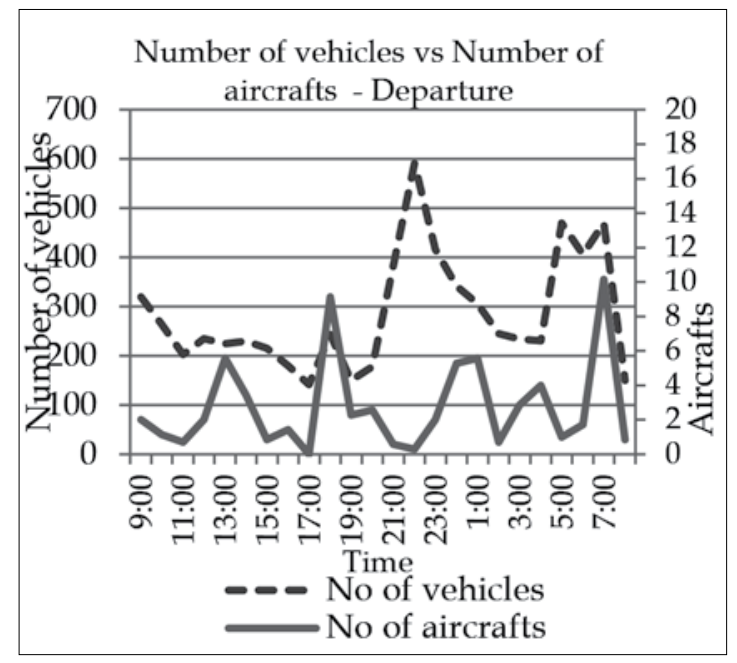

Figure 4- Vehicles vs Aircrafts

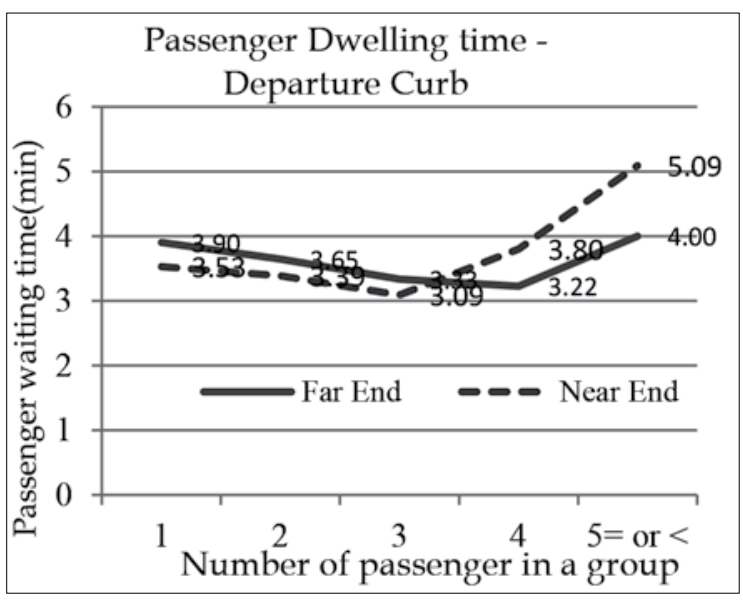

Figure 5 - Departure passenger dwellings
There is significance behavioral difference between foreign and local air passengers with respect to staying time at the curb. Foreign passengers directly move in to the terminal without staying at the curbasoppose to local passengers.

\subsection{Terminal Car park}

There are 284 slots available for cars and dual purpose vehicles with respective parking fees of LKR 150 and LKR 230 for three hour duration. Around 15-20 airport arrival counter based taxies stay at a given moment for much longer durations. The maximum vehicle accumulation of 220 vehicles/hour recorded in 0:00 to 01:00 hours. The vehicle entries gradually increase since 22:00 hours and sometimes it creates longer queues at the park entrance. Further, the accumulated number of vehicles reduces gradually from 01:00 hours in the morning.

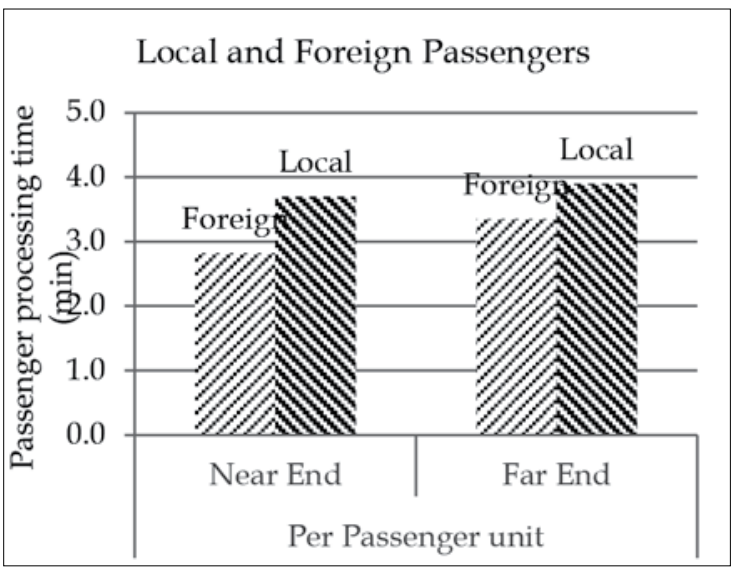

Figure 6 - Departure curbside local and foreign passenger behavior

Even though tickets are issued for three hours; vehicles are able to stay more than three hours due to unavailability of proper system to check parking durations. However, vehicles generally do not stay longer than three hours except taxi cars. On average $45 \%$ of vehicles stay less than 1 hour during day or night times and $7-10 \%$ of vehicles stay over 4 hours in both cases.

\subsection{Vehicle Queues}

Vehicle queues can be seen during typical busy hours and the rest of the times occasional local queues can be seen due to vehicle and passenger obstructions such as pedestrian crossings and unnecessary parking efforts such as vehicles or passengers preferences. 


\section{Departure Porch}

Departure curbside vehicle queues create during 21:00 to 23:00 hour period. However, there are random queues due to parking attempts of vehicles at the close proximity to the terminal entrance door for more convenient passenger and baggage handlings. As a result, curbside area close to terminal entrance door and the first half of the curbside shows more vehicle congestion and passenger operation. On average there are nine vehicles at the departure porch entrance in a given time during the typical busy hour.

\section{Arrival Porch}

Average vehicle accumulation at the entrance of the arrival curbside is 6 vehicles at a time. The average queue length is 4 vehicles during the day time, from 9:00 to 10:00 hours (typical busy hour in day time) when the busiest in day time. Loading of duty free items and passenger and movement of duty free items though pedestrian crossings create obstructions to arrival vehicle flow and results vehicle queues.

\section{Terminal car park entrance}

At the terminal car park where the highest vehicle entries recorded at 22:00-23:00 hours and vehicle queues develop in that particular hour. There is fixed $1-2$ minute vehicle processing time at the entrance for ticket issuing and averagely there are 11 vehicles in the queue in each minute of the particular busy hour. There is 280 seconds of waiting time at the car park entrance vehicle queue.

\section{Analysis of Field Survey Data}

\subsection{Vehicle Queues formation}

The estimation use the random arrival, random services and single service channel (M- M -1) method and estimate under the Poison's distribution.

\section{Departure porch Entrance}

The estimated average vehicle queue is 10 of vehicles and during the typical busy hour and the estimated average queuing time is 121 seconds at the departure porch entrance. This is almost similar to the average 9 vehicles per hour of vehicle queue observed during the field survey. Further, cumulative probability results prove that there is $8 \%$ probability no vehicle queues at the porch entrance and it is $90 \%$ probability that the vehicle queue will be less than 26 vehicles at a time. If there are two service channels which encourage simultaneous entry, will reduce to 3.7 second of queuing time having considerable time saving in the queue and no vehicle queues at all.

\section{Arrival Porch Entrance}

The estimates for the vehicle queue at the arrival porch show 6 vehicles at a time while average queuing time of 66 seconds. The field observations shows the average vehicle queue as 7 vehicles in the typical busy hour. There is $13 \%$ of tendency for zero queue and $90 \%$ confidently says that there will not be more than 15 vehicles.

\section{Terminal Car park}

Terminal car park highest efficiency is 55\% during the night and $45 \%$ during the day time, which implies terminal car park facility is capable for catering the current parking demand. The average parking durations are 2.19 and 2.31 hours respective for day and night times.

\subsection{Airport roadway facility}

Airport curbside road facility analysis is evaluated by using the methods of curbside utilization factor or the volume to capacity basis. Curbside length requirements are evaluated considering hourly vehicle flow rate, dwelling times, and required stall lengths (7.6 meters for cars). The required stall length (139.2 $\mathrm{m})$ and available curb length $(140 \mathrm{~m})$ is found for the busiest hours where highest demand creates. The existing roadway utilization factor, the ratio between the required curbside requirement and available curbside length, is introduced.

\section{Departure curbside roadway}

It was revealed from the analysis that the factor of curbside utilization is 0.994 for the departure curbside roadway. Even the worst case of departure curbside demand, the departure curbside is good enough to keep in safe margin of 1.7 .

\section{Calculation:}

Departure curbside double parking is prohibited and it is a four lane road segment. The peak hour vehicle flow rate $=296 \mathrm{veh} / \mathrm{hr}$ Dwell Time $\quad=2.97 \mathrm{~min}$

Vehicle stall length $\quad=7.6 \mathrm{~m}$

$\mathrm{Ra}=($ Vehicle flow rate $\times$ Dwell time $) / 60$.....(1)

$=(296 \times 2.97) / 60=14.65$

$\mathrm{F}($ constant) $=1.25 \quad$ (3for less than 5 , or 1.2 for 100 or more)

Required Stall length $(\mathrm{K})=\mathrm{Ra} \times \mathrm{F}$.

$$
=14.65 \times 1.25=18.32
$$


Design length $\quad=18.31 \times 7.6=139.2 \mathrm{~m}$

Existing curb length $\quad=140 \mathrm{~m}$

Curbside utilization factor $=$

(Design length / Existing curb length) ... . .

$$
=0.994
$$

\section{Arrival curbside roadway}

The five lanes arrival curbside roadway, if double parking is concerned as currently BIA allowed, the curbside utilization ratio is 1.24 during the busiest hour. Further management decision on double parking at the arrival curbside increase its service level and even in the highly congested hour service level is within acceptable levels as per the calculations.

\section{Airport weaving section roadway}

Roadway weaving section disturbs the movement of non-weaving vehicle movement. The field survey at the weaving section was carried out during both peak and off peak hours. Vehicles flow at the weaving section make somewhat complicated movement, however, it is unidirectional.

The weaving vehicles which make directional change from departure curbside inner lane to arrival curb bypass lane and from departure curb bypass lane to arrival curb inner lane. Non weaving vehicles are the vehicles moving without any lane changes. The field observations found averagely $55 \%$ of weaving vehicles and $45 \%$ of non-weaving vehicles out of the total vehicle movements through the weaving section in both peak and off peak hours. BIA's weaving section configuration is one sided ramp weaving.

\section{Calculation (as per ACRP, 2010):}

Average speed of weaving vehicles within the weaving segment, $S w$

$S w=S \min +[\operatorname{Smax}-\operatorname{Smin}] /[1+w]$

$S_{\max }-$ Maximum average speed expected in the weaving segment

$\mathrm{S}_{\min }$ - Minimum average speed expected in the weaving segment

Form BIA its $S_{\min }=16 \mathrm{~km} / \mathrm{hr}, S_{\max }=40 \mathrm{~km} / \mathrm{hr}$,

$$
S_{\mathrm{w}}=34.9 \mathrm{~km} / \mathrm{hr}
$$

Average speed of non-weaving vehicles in weaving segment, $\mathrm{S}_{\mathrm{NW}}$

FFS - Free flow speed $=32 \mathrm{~km} / \mathrm{hr}$

$\mathrm{v}-$ Equivalent passenger car units $=$

$1203.49 \mathrm{pc} / \mathrm{hr}$

$\mathrm{N}-\mathrm{No}$ of lanes within the weaving segment $=3$

$S N w=F F S-[0.0072-$ LCmin $]-[0.0048-$

$\left.\left(\frac{v}{N}\right)\right]$

$\mathrm{S}_{\mathrm{Nw}}=21.28 \mathrm{~km} / \mathrm{hr}$
Average vehicle speed weaving segment, $S$ $\mathrm{V}_{\mathrm{w}}=$ Non weaving demand flow rate in the weaving segment

$\mathrm{V}_{\mathrm{NW}}=$ Weaving demand flow rate in the weaving segment

$$
\begin{aligned}
& S=\frac{(V w+V n w)}{\left[\left(\frac{V w}{S n}\right)+\left(\frac{V n w}{S n w}\right)\right]} \\
& \mathrm{S}=27.12 \mathrm{~km} / \mathrm{hr}
\end{aligned}
$$

Density by Segment, $S$

$\mathrm{V}=$ Equivalent passenger car units (pc/hr)

$$
D=\frac{\left[\frac{v}{N}\right]}{S} \text {. }
$$$$
\mathrm{D}=23.66 \mathrm{pc} / \mathrm{km}
$$

Heavy vehicle adjustment and driver familiarity are 0.976 and 0.992 respectively. The equivalent passenger car unit (pcu) of 1095 with 1.2 of safety factor is used for the analysis. BIA's weaving section length $90.9 \mathrm{~m}$ and effective three numbers of lanes are in operation.

As found from the above macroscopic method calculations, BIAs' waving segment theoretical vehicle speeds for weaving vehicles and nonwaving vehicles are $34.9 \mathrm{kmph}$ and $21.3 \mathrm{kmph}$ respectively. It was obvious that non-weaving vehicle speeds are slightly lower than the weaving vehicles which could be observed at the field by the survey team. The average vehicle speed in the BIA's weaving section is 27 kmph.

\section{Airport terminal car park performance}

Car park performance analysis mainly focus on parking volume, parking load and parking turn over are the key indicators (MitavChaturvedi, 2012). The evaluation results are tabulated as below.

Table 1 - Terminal Car park performance

\begin{tabular}{|l|c|c|}
\hline Parameter & $\begin{array}{c}\text { Day } \\
\text { Time }\end{array}$ & $\begin{array}{c}\text { Night } \\
\text { Time }\end{array}$ \\
\hline Parking volume (veh) & 525 & 404 \\
\hline Parking load (veh hour) & 1150 & 935 \\
\hline Average parking duration (hrs) & 2.19 & 2.31 \\
\hline $\begin{array}{l}\text { Parking turn over } \\
\text { (veh/hr/bay) }\end{array}$ & 0.21 & 0.24 \\
\hline Parking efficiency \% & 45 & 55 \\
\hline
\end{tabular}

\subsection{Future Demand}

BIA presently handles 7 million total annual passenger volume with corresponding 46,484 aircraft operations. If there will not be any 
roadway facility expansion, the gradually increasing passenger demand will gradually reach its capacity and even up to year 2020 the capacity is sufficient.

The existing roadway facilities are sufficient to cater to the current demand even in highly congested hours, with a sufficient buffer. It is up to maximum 23 aircraft movement are able to be operated with the existing roadways facilities. However those 23 aircrafts limited to 23 arrivals or it will limit to 15 numbers of departures flights due to departure curbside roadway constraints. Therefore the current BIA access roadway level of service is sufficient to cater the demand up to year 2020 and even in year 2020 it will cater satisfactory level of service

\section{Conclusion}

The field data show the behavior of passengers, vehicles and choice models of air and vehicle passengers. This particular data analysis further implies the relationships in between the different behavioral patterns such as departure aircrafts and departure curbside vehicle accumulation, etc.

The survey results found that the access road average total vehicle count 7100 veh/ day and the maximum vehicle count recorded as 591 veh/hr during 21-22 hour. Similarly the total vehicle counts for arrival and departure porches were 3702 veh/day and 2980 veh/day respectively and their maximum hourly counts were $329 \mathrm{veh} / \mathrm{hr}$ and $296 \mathrm{veh} / \mathrm{hr}$. Furthermore, the average vehicle dwelling times on arrival and departure curbsides are 2.3 mins and 3.0 mins in their typical busy hours.

In case of passenger behaviors at curb sections, passenger dwellings, passenger waiting times and vehicle occupancy levels are important parameters. There are 2.2 air passengers in a vehicle leaving from the arrival curb and that of 1.5 average air passengers coming to the departure curbside in a single vehicle. Further, the survey could be found that the staying time of departure passengers are much higher when they are in groups. It is clear that there is a significance difference between local and foreign passengers staying times at the departure curb. Furthermore, it is noticeable fact that parameters of "vehicle passengers per vehicle", "number of baggage per air passenger" and "vehicle waiting time at the curbside for an air passenger" do not change with their model choice.
The data analysis can be used as a source for level of service analysis of airport roadway and parking facilities. Furthermore, for capacity planning and facility improvement can be guided by these results since which were taken as fully raw data from the airport facilities. It is noticeable that the all calculation results are much similar with the field data directly gathered at the survey.

The projected passenger and vehicle demand is useful to evaluate facility demand and the adequacy of current facilities for the expected demand. The calculations will be under the service level evaluation for predicted passenger demand in year 2020. This particular passenger projection used logistic method and passenger growth rate for last 6 years is the basis to logistic method prediction. The estimation revealed that 14 million passenger movement in year 2020 (this calculation is almost similar to the AASL estimations) and BIA should provide the facilities to prevent demand reach facility capacity. The existing roadway facilities will not be sufficient for such a high demand and therefore some changes have been identified to calm the situation. The main operational issue is identified as the non-utilization of full curbside length of both arrival and departure curbs where some of the spaces allocated for some special occupants such as taxies, etc and some spaces have neglected due to inconveniences to passenger and vehicle dwellings. These neglected curbside lengths should be utilized efficiently and this study strongly recommends that those adjustments will double the curbside facility and resolve the issue considerably. There is an enough space already having in the arrival curbside area and no major changes would be performed. That particular evaluation will lead to continual improvement of facilities without making any bottle necks to user behaviors in the BIA roadway system.

\section{References}

[1]. Transport Research Board, Airport curbside \& Terminal Area roadway operations, Airport Cooperative Research Program (ACRP), USA, 2010.

[2]. Ashford, N., "Level of Service Design Concept for Airport Passenger Terminals : A European View". Transportation Research Record, volume 1199, 1988.

[3] Creswell, \& John, C., "Research Design Qualitative \& Quantitative Approaches". ThousandOaks:SagePublication, 1994. 
[4] Ashford, N., Hawkins, N., O' Leary, M., Bennetts, D., \& McGinity, P., "Passenger Behaviour and Design of Airport Terminals". Transportation Research Record, volume 588, 1976.

[5] Ghobrial, A., and Kanafani, A., "Future of AirlineHubbed Networks: Some Policy Implications", Journal of Transportation Engineering, 1995.

[6] MitavChanturvedi, "A Geospatial analysis of efficiency of the parking system in Enschede", Netherlands, 2012.

[7] Civil Aviation Authority, Progress Report, Ministry of civil Aviation, Sri Lanka, 2012.
[8] James H Banks, Introduction to transportation engineering. Tata Mc-Graw Hill, 2004.

[9] Frederick, S., Hillier and Gerald, J. Lieberman, Operations Research. CBS publishers, 2009.

[10] Adolf, D., May, Fundamentals of Traffic Flow. Prentice - Hall, Inc. Englewood Cliff New Jersey 07632, second edition, 1990.

[11] Papacostas, C.S., Transportation engineering and planning by Papacostas. C. S, 3rd edition, 2001.

[12]

http://cedb.asce.org/cgi/WWWdisplay.cgi?9403862 ,12th December 2013 
